\title{
Improving evaluation of climate change impacts on the water cycle by remote sensing ET-retrieval
}

\author{
SANDRA G. GARCÍA GALIANO', PATRICIA OLMOS GIMÉNEZ ${ }^{1}$, \\ JOSÉ ÁNGEL MARTÍNEZ PÉREZ ${ }^{1}$, JUAN DIEGO GIRALDO OSORIO \\ 1 Department of Civil Engineering, Universidad Politécnica de Cartagena, Paseo Alfonso XIII, 52, 30203, Cartagena, \\ Spain \\ sandra.garcia@upct.es \\ 2 Department of Civil Engineering, Pontificia Universidad Javeriana, Bogotá, Colombia
}

\begin{abstract}
Population growth and intense consumptive water uses are generating pressures on water resources in the southeast of Spain. Improving the knowledge of the climate change impacts on water cycle processes at the basin scale is a step to building adaptive capacity. In this work, regional climate model (RCM) ensembles are considered as an input to the hydrological model, for improving the reliability of hydroclimatic projections. To build the RCMs ensembles, the work focuses on probability density function (PDF)-based evaluation of the ability of RCMs to simulate of rainfall and temperature at the basin scale. To improve the spatial calibration of the continuous hydrological model used, an algorithm for remote sensing actual evapotranspiration (AET) retrieval was applied. From the results, a clear decrease in runoff is expected for 2050 in the headwater basin studied. The plausible future scenario of water shortage will produce negative impacts on the regional economy, where the main activity is irrigated agriculture.
\end{abstract}

Key words regional climate models; ensembles; actual evapotranspiration; remote sensing-retrieval; climate change impacts; rainfall-runoff modelling; NDVI-land surface temperature space.

\section{INTRODUCTION}

The Segura River basin (SRB), located in southeast Spain, is a drought-prone region with an irrigated agricultural water demand of $85 \%$ of the total water demand in the entire basin. Water scarcity is a major issue in the SRB. Therefore the generation of resources from non-traditional sources (such as desalination), and the improving of water-use efficiency are vital options for the support of the regional economy.

According to several authors such as Huntington (2006), there is robust evidence of current and future intensification of the hydrological cycle. In Spain it is a priority to increase the availability of regionalized scenarios of future climate change for performing risk analyses and impact assessment at the basin scale to build adaptive capacity. The evaluation of the uncertainties associated with greenhouse gases emissions (GHG) scenarios on hydrological projections will increase the reliability of the models. The uncertainty due to the hydrological model used generally is relatively small compared to the uncertainty from GHG scenarios and climate models (Prudhomme and Davies, 2009).

For increasing the reliability of climate and hydrological projections at basin scale, ensemble methodologies of regional climate models (RCMs) are proposed. The biases are reduced and global climate model (GCMs) simulations are improved by RCM ensembles (Diallo et al., 2012). However, it is not possible to conclude which RCM seems to be the most reliable; a comprehensive assessment of climate change projections needs to be based on the information provided by the RCM ensembles for simulating the variability of the temperature, according to Giorgi and Mearns (2002) and Xu et al. (2010). The RCM ensembles help to compensate systematic errors from both the nested and the driving models.

In this work, a robust methodology is proposed for building the RCM ensembles for several variables (monthly rainfall and maximum, minimum and mean temperatures). The objective is to improve the projections of components of the water cycle (such as runoff and actual evapotranspiration), considering the RCMs ensembles as input to a spatially distributed continuous hydrological model. For building the RCM ensembles, the work focuses on probability density function (PDF)-based evaluation of the ability of RCMs to simulate rainfall and temperature at basin scale. With the purpose of spatial calibration of the hydrological model, a methodology for assessment of actual evapotranspiration (AET) from remote sensing is validated. 


\section{STUDY AREA AND DATASETS}

The study region corresponds to the Fuensanta basin, a headwater basin of the Segura River basin (SRB), located in southeast Spain (Fig. 1). The variability of rainfall in the SRB is high, with annual values ranging from $300 \mathrm{~mm}$ on the coast to over $1000 \mathrm{~mm}$ in the mountains. The SRB has a surface area of $18879 \mathrm{~km}^{2}$, while Fuensanta basin covers an area of approximately $1220 \mathrm{~km}^{2}$. The dominant climatic influence is Mediterranean. The annual potential evapotranspiration in the area is $1500 \mathrm{~mm}$. The SRB is considered semi-arid and arid at the coast.

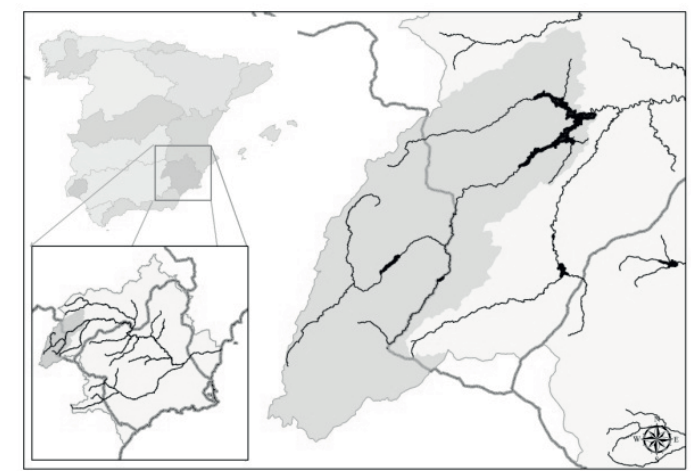

Fig. 1 Location of Segura River basin in the Iberian Peninsula, and detail of Fuensanta basin.

Grids of historical daily temperatures and rainfall for Spain (based on the Spain02/V2.1 dataset) with a spatial resolution of $0.2^{\circ}$ (Herrera et al., 2010), were considered for the time period 1951-2012. Then, RCM data for Europe provided by the ENSEMBLES ProjectRT2B (Christensen et al. 2009) were used. The selected RCMs with a spatial resolution of $25 \times 25 \mathrm{~km}$ were worked with for the time period 1961-2050. The following sixteen RCMs, driven by different GCMs for scenario A1B, were selected: C4IRCA3, CNRM/RM5.1, DMI/ARPEGE, DMI/ECHAM5-r3, DMI/BCM, ETHZ/CLM, ICTP/REGCM3, KNMI/RACMO2, METNO/BCM, METNO/HADCM3Q0, MPI-M/REMO, OURANOS/MRCC4.2.1, SMHI/BCM, SMHI/ ECHAM5-r3, SMHI/HadCM3Q3, UCLM/PROMES. Based on the grid provided by the RCMs dataset, 906 sites for analysis were setup. For the remote sensing retrieval of AET, several products from the MODIS TERRA sensor were processed for time period 2000-2012, such as land surface temperature (LST), normalized difference vegetation index (NDVI), and surface reflectances. Table 1 presents a summary of the different datasets.

Table 1 Time periods of datasets.

\begin{tabular}{ll}
\hline Description & Time period \\
\hline Observed meteorological dataset & $1951-2012$ \\
RCMs & $1961-2050$ \\
Remote sensing data & $2000-2012$ \\
\hline
\end{tabular}

\section{BUILDING PDF ENSEMBLE ON SITE}

In the present work, a revised method based on the Reliability Ensemble Averaging (REA) method (Giorgi and Mearns, 2002), is addressed. The REA method provides a measure of reliability, average and uncertainty range of simulated climate change from ensembles of RCMs. Xu et al. (2010) presented a new structure of the ensemble considering several meteorological variables, which abandons the use of the convergence criterion. The computations of weighting factor $R_{i}$ are based on empirical cumulative distributions (e-CDF) and the $p$ value of the well-known twosample Smirnov-Kolmogorov test (Sheskin, 2000). The $R_{i}$ values are estimated based on seasonal and yearly CDFs as follows:

$$
R_{i}=\left(\text { Winter }^{a} \cdot \text { Spring }^{b} \cdot \text { Summer }^{c} \cdot \text { Autum }^{d} \cdot \text { Year }^{e}\right)^{1 / a+b+c+d+e}
$$


where the parameters $a, b, c, d$ and $e$ are the criterion weights. The likelihood associated with a simulated change for the RCM is proportional to the model reliability factor $R_{i}$. The normalized reliability factors, $P_{m}$, can be interpreted as this likelihood associated with each RCM. For the building of the PDF ensemble for each site, greater weight was given to RCMs with a high value of the normalized reliability factor, using bootstrapping techniques.

The CDF for maximum, minimum and mean monthly temperatures, and for rainfall (19612050 time period) were obtained from the observed dataset and RCMs throughout Spain (906 sites). As an example, Fig. 2 represents the CDFs for each RCM, observed dataset, and ensemble for the seasonal and annual rainfall on site 732 (Fuensanta basin). Then, multimodel ensembles were built for the time period 2021-2050, as an input to the hydrological model at monthly scale.
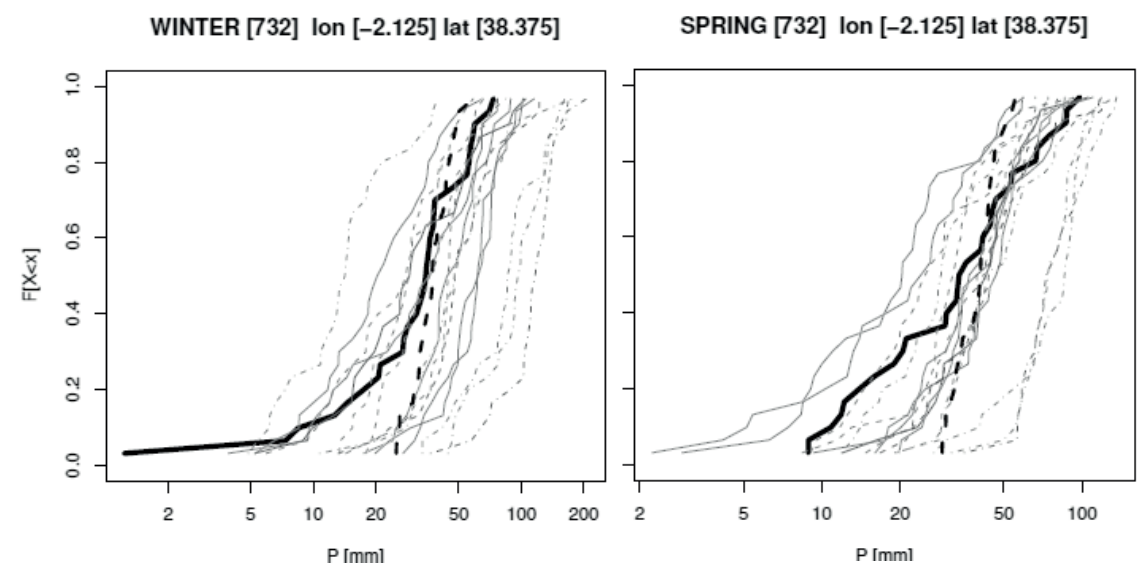

SUMMER [732] Ion [-2.125] lat [38.375]

AUTUMN [732] Ion [-2.125] lat [38.375]
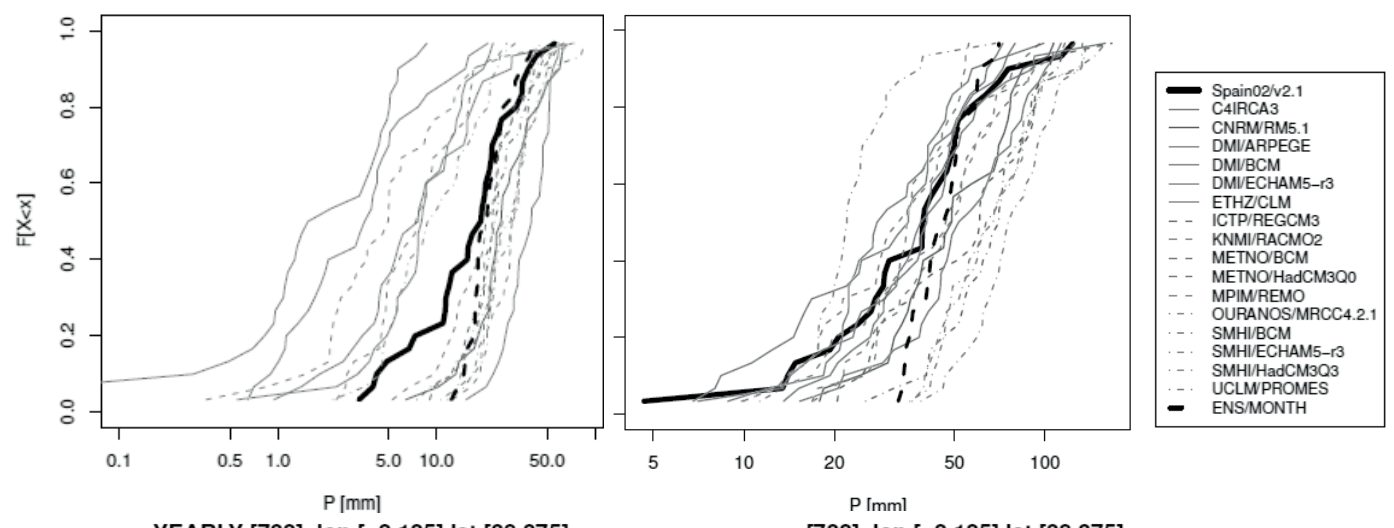

YEARLY [732] Ion [-2.125] lat [38.375]
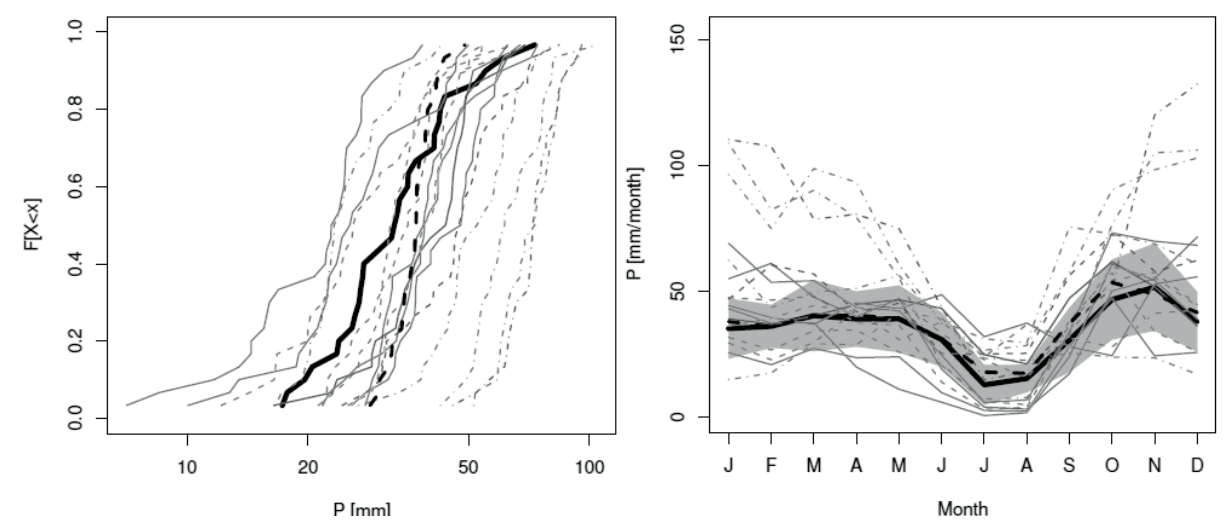

Fig. 2 Seasonal and annual CDFs of rainfall on site 732, from observed dataset (in black), ensembles (dashed black) and RCMs. Time period: 1961-1990. 


\section{HYDROLOGICAL MODEL}

The spatially distributed hydrological model used, based on the Témez (1977) model, corresponds to a monthly water balance model with few parameters. The water from rainfall that is not retained in the soil's upper layer, and that does not evaporate, infiltrates into the aquifers and, simultaneously, is responsible for the superficial runoff process. The parameters (maximum soil holding capacity, maximum infiltration rate, runoff coefficient and aquifer discharge coefficient), were estimated using several years of observed data, and thematic cartography. The equations of the hydrological model are applied to each cell, by embedding the model algorithms in a GIS. As output the model generates the spatial distributions of runoff, infiltration and soil water.

The spatial distribution of potential evapotranspiration (PET), as an input to the hydrological model, was estimated applying a modified method based on the Hargreaves model (Hargreaves and Samani, 1985; Maestre et al., 2013).

\section{REMOTE SENSING ACTUAL EVAPOTRANSPIRATION RETRIEVAL}

For assessment of spatial distributions of daily AET from the satellite images, a graphical method proposed by Jiang and Islam (2001) based on the interpretation of the LST versus NDVI space was applied. This method applies the interpolation of Priestley and Taylor (1972), requiring few local data. The scatter plot of $L S T$ vs NDVI usually presents a triangular shape whose boundaries are interpreted as limiting surface fluxes (Fig. 3(a)). The upper edge or dry edge of the triangle represents limiting conditions of soil moisture and minimum ET. This contrasts with the lower edge or wet edge that corresponds to maximum ET. The linear interpolation between the edges of the $L S T-N D V I$ space allows the estimation of $\phi$ values for each pixel as follows:

$$
\Phi=\Phi_{\max } \frac{L S T_{\max }-L S T}{L S T_{\max }-L S T_{\min }}
$$

where $L S T_{\max }$ and $L S T_{\min }$ are the highest and lowest land surface temperatures in each narrow $N D V I$ class (which corresponds to the lowest and highest evaporation rates, respectively).

The Priestley-Taylor expression for AET is given by:

$$
A E T=\Phi\left[\frac{\Delta}{\Delta+\delta}\right]\left(R_{N}-G\right)
$$

where $\Delta\left(\mathrm{Pa} \mathrm{K}^{-1}\right)$ is the slope of the saturated vapour pressure curve at the prevailing air temperature (Ta), $\delta$ is the psychrometric constant $\left(\mathrm{Pa} \mathrm{K}^{-1}\right)$, and $\Phi$ is the (dimensionless) PriestleyTaylor parameter which is generally interpreted as the ratio between actual ET and equilibrium ET ( $\Phi$ parameter is assumed to be 1.26 for wet land surface conditions), and $R_{N}$ the net radiation. The heat soil flux $(G)$ is estimated by the approach proposed by Tanguy et al. (2012).
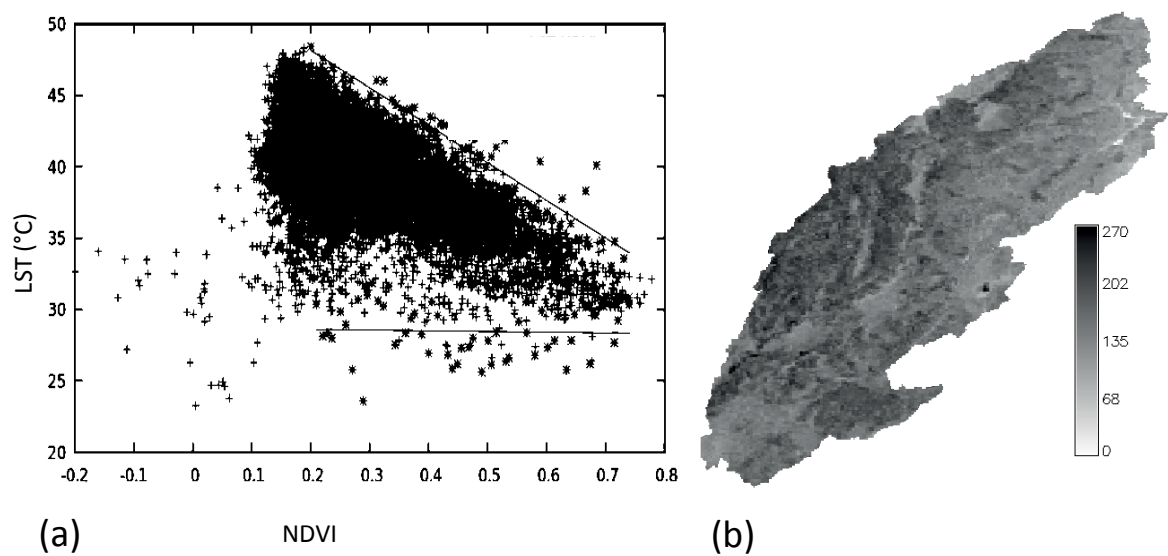

(b)

Fig. 3 Assessment of AET: (a) LST-NDVI space for SRB on 5 June 2001; and (b) map of monthly AET (mm) for Fuensanta basin on July 2004. 


\section{DISCUSSION OF RESULTS}

\section{Calibration and validation of the hydrological model}

The Témez hydrological model was calibrated and validated considering historical meteorological and hydrological datasets for the Fuensanta basin. The performance analysis was based on graphical and numerical goodness of fit. Figure 4 presents the hydrographs obtained in the calibration (Fig. 4(a)) and validation phase (Fig. 4(b)). The monthly Nash Sutcliffe efficiency index exhibited satisfactory results, reaching a value of 0.71 for the calibration phase (2000-2005), and 0.68 for the validation phase (2006-2012).
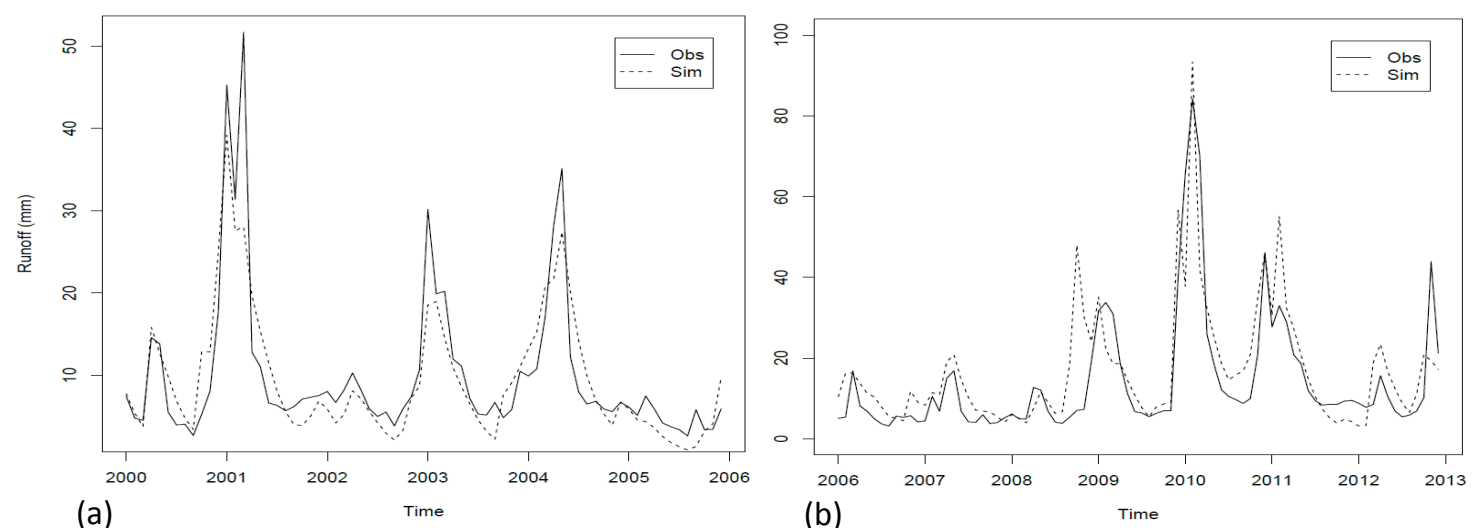

Fig. 4 Observed and simulated runoff (mm) for Fuensanta basin: (a) calibration for 2000-2005 period; and (b) validation for 2006-2012 period.

In the comparison between the $A \mathrm{ET}$ spatial distributions obtained from remote sensing (Fig. 3(b)) and simulated by the hydrological model (not shown), the differences in some cases were over $100 \%$. Therefore, the algorithm used in the model for assessment of AET was adjusted according to the remote sensing results.

\section{Projection of runoff and rainfall}

Considering the monthly ensembles of rainfall and potential evapotranspiration, as an input to the hydrological model, improved runoff projections were obtained for the periods 2021-2050. Analysing the mean annual runoff variation between the observed data for 1961-1990 and that simulated for the 2021-2050 time period on the Fuensanta basin (Table 2), a plausible runoff decrease of over $13 \%$ is expected. The results are very sensitive to the period selected for comparison. Short records could not reflect long-term climate trends. As an example, if the comparison is based on the 1983-2012 period, the expected trend of runoff would be positive because a severe drought was observed in the years 1991 to 1995 . Therefore, the selection of the time period for building hydroclimatic projection ensembles and analysing trends is a key issue.

Table 2 Contrast of mean annual runoff, rainfall and PET for Fuensanta basin.

\begin{tabular}{lllll}
\hline Data & Period & Mean annual runoff $(\mathrm{mm})$ & Mean annual rainfall $(\mathrm{mm})$ & PET $(\mathrm{mm})$ \\
\hline Observed & $1961-1990$ & 209 & 631 & 1429 \\
Ensemble & $2021-2050$ & 182 & 658 & 1487 \\
Variation & & $-13 \%$ & $4 \%$ & $4 \%$ \\
\hline
\end{tabular}

\section{CONCLUSION}

For understanding plausible impacts of climate on hydrological processes, RCMs are a valuable tool. However, there are divergences between the climate models projections. Then, the multimodel ensemble approach allows the quantification and reduction of uncertainties in the 
predictions. In the present work, a robust methodology for building climate multimodel ensembles of meteorological data was presented. The final aim was to increase the reliability of both climatological and hydrological projections.

The introduction of GIS has facilitated the spatial modelling of the water cycle. Understanding and predicting the impacts of climate change using physically-based distributed rainfall-runoff models, introduces several uncertainties due to the usually high number of parameters considered. Therefore, in this work a spatially distributed rainfall-runoff model with few parameters at monthly scale, embedded in a GIS, was applied in order to increase the reliability.

The remote sensing-retrieval of AET was found to be a suitable methodology for improving the spatial calibration of some outputs of the hydrological model. However, further work is needed to assimilate this type of data into the hydrological modelling proposed.

Taking into account a PDF ensemble from RCMs of rainfall as well as temperatures, a plausible scenario of significant decreases of runoff for 2050 is expected on the SRB. As it was demonstrated in the present work, the long-term hydroclimatic trend is sensitive to the selection of the records for comparison.

Increasing knowledge about plausible impacts of climate change on components of the hydrological cycle at basin scale is an important step in building adaptive capacity to the impacts on southern Spain.

Acknowledgements This work was developed in the framework of R\&D Project CGL201239895-C02-01 HYDROCLIM, financed by the State Secretary of Research of the Spanish Ministry of Economy and Competitiveness (MINECO) and FEDER funds. The funding received is gratefully acknowledged.

\section{REFERENCES}

Christensen, J. H., Rummukainen, M. and Lenderink, G. (2009) Formulation of very high-resolution regional climate model ensembles for Europe. In: ENSEMBLES: Climate change and its impacts at seasonal, decadal and centennial timescales: Summary of research and results from the ENSEMBLES project, edited by: van der Linden, P. and Mitchell, J. F. B., Met Office Hadley Centre, FitzRoy Road, Exeter EX1 3PB, UK, 47-58.

Diallo, I., et al. (2012) Multimodel GCM-RCM ensemble-based projections of temperature and precipitation over West Africa for the early $21 \mathrm{st}$ century. Hindawi Publishing Corporation. International Journal of Geophysics doi:10.1155/2012/972896

Giorgi, F. and Mearns, L. O. (2002) Calculation of average, uncertainty range, and reliability of regional climate changes from AOGCM simulations via the "reliability ensemble averaging" (REA) method. J Clim. 15(10), 1141-1158.

Hargreaves, G. H. and Samani, Z.A. (1985) Reference crop evapotranspiration from temperature. Applied Eng. in Agric. 1(2), 96-99.

Herrera, S., et al. (2010) Development and analysis of a 50-year high-resolution daily gridded precipitation dataset over Spain (Spain02). Int. J. Climatol. doi:10.1002/joc.2256.

Huntington, T. G. (2006) Evidence for intensification of the global water cycle: review and synthesis. J. Hydrol., 319, 83-95.

Jiang, L. and Islam, S. (2001) Estimation of surface evaporation map over southern Great Plains using remote sensing data. Water Resources Research, 37(2), 329-340.

Maestre-Valero, J.F., Martínez Alvarez, V. and González Real, M.M. (2013) Regionalization of the Hargreaves coefficient to estimate long-term reference evapotranspiration series in SE Spain. Span. J. Agric. Res. 11(4), 1137-1152.

Priestley, C. H. B. and Taylor, R. J. (1972) On the assessment of surface heat flux and evaporation using large scale parameters. Monthly Weather Review 100, 81-92.

Prudhomme, C. and Davies, H. (2009) Assessing uncertainties in climate change impact analyses on the river flow regimes in the UK. Part 2: future climate. Clim. Change 93, 197-222, doi: 10.1007/s10584-008-9461-6.

Sheskin, D. J. (2000) Handbook of parametric and nonparametric statistical procedures, 2nd ed. Chapman \& Hall/CRC, Boca Raton.

Tanguy, M., et al. (2012). A new parameterisation scheme of ground heat flux for land surface flux retrieval from MODIS products. J. Hydrol. 454-455, 113-122.

Témez, J. R. (1977) Modelo Matemático de trasformación “precipitación-escorrentía. Asociación de Investigación Industrial Eléctrica.ASINEL. Madrid. 39 pp.

$\mathrm{Xu}, \mathrm{Y}$., Gao, X. and Giorgi, F. (2010) Upgrades to the reliability ensemble averaging method for producing probabilistic climate-change projections. Clim. Res. 41, 61-81. 